\title{
Biofouling protection for marine underwater observatories sensors
}

\author{
L. Delauney ${ }^{1,{ }^{*}}$, C. Compère ${ }^{2}$ and M. Lehaitre ${ }^{2}$ \\ ${ }^{1}$ In-Situ Measurement and Electronics Group, Ifremer, B.P. 70, 29280, Plouzané, France \\ ${ }^{2}$ Interfaces and Sensors Group, Ifremer, B.P. 70, 29280, Plouzané, France \\ *: Corresponding author : Laurent Delauney, email address : laurent.delauney@ifremer.fr
}

\begin{abstract}
:
These days, many marine autonomous environment monitoring networks are set up in the world. These systems take advantage of existing superstructures such as offshore platforms, lightships, piers, breakwaters or are placed on specially designed buoys or underwater oceanographic structures. These systems commonly use various sensors to measure parameters such as dissolved oxygen, turbidity, conductivity, $\mathrm{pH}$ or fluorescence. Emphasis has to be put on the long term quality of measurements, yet sensors may face very short-term biofouling effects. Biofouling can disrupt the quality of the measurements, sometimes in less than a week.
\end{abstract}

Many techniques to prevent biofouling on instrumentation are listed and studied by researchers and manufacturers. Very few of them are implemented on instruments and of those very few have been tested in situ on oceanographic sensors for deployment of at least one or two months.

This paper presents a review of techniques used to protect against biofouling of in situ sensors and will give a short list and description of promising techniques.

\section{Introduction}

Biofouling has long been considered as a limiting factor in ocean monitoring requiring the placement of any materials under water. Many potential solutions to this problem have been proposed (Manov et al., 2004) but none seems to be universally applicable.

During the last 20 years, many marine monitoring stations have been developed aiming at either collecting data to calibrate satellite observations or for coastal water quality assessment. Most of them are surface buoys or subsurface moorings. These systems are now equipped with sophisticated sensing equipment. Sensors, housings and support structures are subject to fouling problems and emphasis has to be put on the long-term quality of measurements that may face very short-term biofouling effects. 
This situation is very complex and must be approached simultaneously in two ways: by the improvement of knowledge of biofouling mechanism (growth and adhesion) and by the development of prevention strategies.

As well, two aspects should be considered, the protection of the sensor housing and the protection of the sensor sensing interface.

In practice, on present instruments, biofouling protection of the housing is rarely taken into account by manufacturers. The materials used and the geometry of the sensor are driven by requirement of the measurement techniques, or mechanical or economic matters rather than optimization of biofouling protection. Current effort is still focused on the protection of the sensing area of the sensor. Nevertheless, intensive research work is performed on the development of self-biofouling protected materials.

The protection of the sensing area of the sensor is a concern that has been tackled for the last decade, operational solutions are now being implemented on commerciall equipment used for longterm deployments. Presently, only three biofouling protection systems for oceanographic sensors can be found on the market :

- Purely mechanical devices such as wipers or scrapers.

- "Uncontrolled" biocide generation system based on the copper corrosion mechanism or tributyltin (TBT) biocide leaching.

- "Controlled" biocide generation systems based on a localized seawater electro-chlorination system or an automatic acid dispensing device. 
These three techniques are commonly used on oceanographic sensors and each of them has, advantages and disadvantages.

Beside these, numerous studies have been performed to develop biofouling protection techniques, some of them show improvement in the laboratory, in an artificial environment, but are inapplicable for sensor protection in a real seawater environment. The reasons can be that the protection is not effective enough, or the material used does not stand seawater environment, or the sensor measurements are adversaly affected by the protection or the cost would be too high.

Biofouling development is explained briefly in the next section, then sensor housing protection techniques are discussed followed by sensor sensing area biofouling protection. For this last section, operational and under development solutions will be discussed separately.

\section{Fouling mechanism}

When a structure is immersed in seawater, it is rapidly covered by unavoidable fouling. This growth is a complex phenomenon and much remains to be understood. In marine environments, over 4000 organisms (Yebra et al., 2004) are related to fouling problems. Organisms may be divided according to their size into micro-organisms (or so called biofilm, slime, micro-fouling) and macro-fouling.

The succession of fouling organisms is generally considered in five main stages :

- the first event is the adsorption of organic and inorganic macromolecules immediately after immersion, forming the primary film;

- second, the transport of microbial cells to the surface, and the immobilization of bacteria on the surface;

- in the third stage, the bacterial attachment to the substratum is consolidated through extracellular polymer production, forming a microbial film on the surface;

- the fourth stage corresponds to the development of a more complex community with the presence of multicellular species, microalgae, debris, sediments, etc. on the surface;

- the last stage is the attachment of larger marine invertebrates such as barnacles, mussels and macro-algae.

However, even though numerous real-life experiments on materials immersed in seawater have been carried out, the existence of a pattern for the attachment of microfouling followed by macro-fouling has been called into question. It now seems that some of these stages may occur in parallel or may be missing. For example, from Roberts (1991), macro-organisms do not necessarily need the presence of a biofilm on a surface to settle.

An important matter about fouling mechanisms is the numerous parameters which influence the development speed and the type of fouling produced. Biofouling development on a surface is the net result of several physical, chemical and biological factors : temperature, conductivity, $\mathrm{pH}$, dissolved oxygen content, organic material content; hydrodynamic conditions; location, season, and depth. Consequently, any protection system faces many non-repeatable phenomena. Thus, specific know-how from users is crucial in order to adapt biofouling protection to the in situ conditions of the particular deployement.

\section{Biofouling protection of the sensor housing}

\subsection{Why the sensor housing should be or should not be protected against biofouling?}

First we must understand the purpose, whey there is a need to protect the sensor housing against biofouling. In the context of in situ measurements there are several reasons.

The most obvious one is to get a clean instrument or at least an "easy to clean" instrument at the end of deployment. This could be thought of as a "comfort of use" 
reason. In many situations, this is not the most important reason. In order to properly deploy sensors for long-term monitoring, metrological calibration must be performed before and after deployment. When the sensors are recovered after deployment, if the sensor housing is fouled, the instruments must be cleaned as soon as they are taken out of the water. If the sensor is hardly fouled mechanical methods such as high pressure water jet or brushes or chemical methods are sometimes used to clean up the instrument. These actions can modify the status of the sensitive sensor area, consequently it will be difficult to compare the metrological response of the sensor before and after the deployment. If the sensor housing is left as fouled as it was when it was recovered, very often, the standard methods used to check the sensor response can be affected, especially if it is an optical sensor. Finally, very often, calibration laboratory working conditions, even for oceanographic sensors, are not really compatible with handling of fouled instruments. Consequently, laboratory check after deployment will not be possible with heavily fouled instruments.

An other reason is to avoid fouling (micro or macro) development in the area of the sensor. Macro-fouling development caused by fouling on the housing of the sensor can disturb the biological and chemical properties of the studied site. For example if the sensor is intended to measure oxygen, its measurements can be affected by macrofouling aggregates that alter the local oxygen concentration. In the same way, fluorescence measurements intended to quantify fluorescence in the water can be affected by the close proximity of fluorescent material on the housing. If this consideration is taken into account, it means that the entire measurement structure must be protected and not only the sensor.

The most obvious reason is macro-fouling for optical sensors and electrochemical sensors. For example, for the optical sensors, even if the sensing area of the sensor is effectively cleaned by a wiper or any other means, if macro algae come through the optical path, the measurements may be subject to random fluctuations (noise) or to offsets. It is particularly true for transmissometers, where the measurement is performed over a long optical path which is very exposed to macro fouling disturbance (Kerr et al, 1998).

Finally, we must be aware that, in some cases, care must be taken in the choice of a prevention method as it can strongly influence the local environment to be monitored, especially when the materials are protected by biocide leaching.

\subsection{Commercially available techniques}

Commercially available techniques to protect the sensor container are mainly based on antifouling paints used for ship hull protection. Adhesive tape or food wrapping film should be mentioned; it's not a proper antifouling system but it can be used to wrap the instrument and by removing the tape it can be cleaned very easily when recovering. In this way the instrument can be sent to the metrological laboratory quite clean.

Antifouling paints with active biocides such as copper compounds, copper oxides and cobiocide chemicals can be used to protect the sensor container. Other biocides are incorporated in antifouling paints in addition to, or in replacement of, copper compounds; these biocides are used for agriculture and are designated as pesticides, algicides or bactericides. Such biocides are not used frequently to protect sensors for ocean monitoring.

Self-polishing paints can be effective to protect the sensor container but only on sites with water flow. As for conventional biocide antifouling paint, self-polishing paints contain biocides and consequently can disrupt the environment to be monitored by the sensor.

An interesting antifouling paint category is non-stick coating. These paints are based on silicone materials or fluorinated polymers. Theoretically, these paints can be biocide free. They are known to be effective to protect ship hulls since the movement of the ship will create sufficient shear forces to remove the fouling. In case of sensor housing protection 
non-stick coatings can help to inhibit fouling growth if the currenmts at the site are sufficient as this will help with cleaning.

\subsection{Techniques under research}

There are many techniques which have been studied to prevent fouling development on materials. For such studies, laboratory tests have been carried out in which fouling inhibition has been reported but very few studies include real marine in situ tests. Very often, the marine environment is so severe for biofouling development that techniques that are not based on conventional antifouling paints are not effective enough to eradicate fouling growth for the duration required. However the growth rate in the first stages of fouling development can be slowed down or it can help in deployment where fouling development is very light.

Whelan et al. (2006), presents a recent evaluation of different antifouling solutions for instrumentation; there are interesting solutions for protection of sensor housings. Marine in situ tests are mentioned in some cases and show reduced fouling growth.

Some of the techniques do not require any external energy such as the use of material impregnated with biocides (polyethylene oxide modified surfaces, Bearinger et al. 2003), grafted with bactericidal polycationic groups (Cen et al., 2003) or the use of polystyrene resin doped with toxic compounds (Wood et al., 1996). Alternatives include the use of copper screening grid to protect the sensor housing. This has been tested in the marine environment and is particularly effective to prevent adhesion of barnacles and oysters (Spears and Stone, 1969)

Coatings with photocatalytic materials (Linkous et al. 2000, Morris et al. 2000) have also been studied. Unfortunately, these coatings are effective only to one meter depth.

Natural antifouling strategies based on chemicals produced by aquatic animals or plants appears very smart and promising to control or reduce the colonization of fouling organisms. According to Chambers (2006), more than 160 natural antifouling products from marine species (algae, sponges, bacteria...) have been identified and are reported as being effective to inhibit surfaces from biofilms and biofouling growth.

Active strategies are also used. Such antifouling methods are based on electromechanical principles. The U.S. Navy patented (U.S. Pat. 4092858, 1978) an oceanographic sensor that vibrates upon excitation by an electric potential, thus removing fouling material from the surface, but the power requirement is too high for autonomous in situ system.

Direct electrification of organisms has also been tested in different ways, by direct transfer of electrons from the electrodes to the fouling organisms, titanium nitride (TiN) electrodes (Nakayama et al. 1998) or graphite-silicones electrodes (Nakasono et al.,1993) have been tested. As well, brief electrical pulses have been studied by AbouGhazala and Schoenbach (2000) as a means to prevent biofouling in cooling water systems.

Finally, temporary immersion of the sensor can be performed in order to slow down biofouling development on sensors housing. This is a complex mechanical scheme and sensors based on membranes such as $\mathrm{pH}$ or oxygen Clark electrodes can take time to stabilize after immersion. Following a similar philosophy, sensors can be parked in a specific " chamber" in which the water is treated with a biocide, With retraction of the sensitive elements into an inert or biocide-filled chamber between measurements (Grisoni et al., 2007).

This technique is complicated to implement and sensors needs to stabilize when they are in the medium for the actual measurement. These two techniques are therefore used very rarely because they need an appropriate mechanical infrastructure. 


\section{Biofouling protection of the sensing area of the sensor.}

\subsection{Effect of biofouling on measurements}

Autonomous monitoring systems should provide in real time reliable measurements without costly and or frequent maintenance. In deep sea conditions this maintenance is nearly impossible to realize. For coastal applications it is quite accepted, that a twomonth interval for maintenance is the minimum duration for economically viable in-situ monitoring systems (Blain et al., 2004). Consequently, systems without efficient biofouling protection are likely to be compromised. The protection must be applied to the sensors and to any underwater communication equipment most often based on acoustic technologies.

Biofouling in seawater, during productive periods (blooms), can grow very rapidly and lead to poor data quality in less than two weeks. As shown on figures 1 and 2 the biofouling species involved can be very different from one location to an other one (Lehaître et al., 2008).

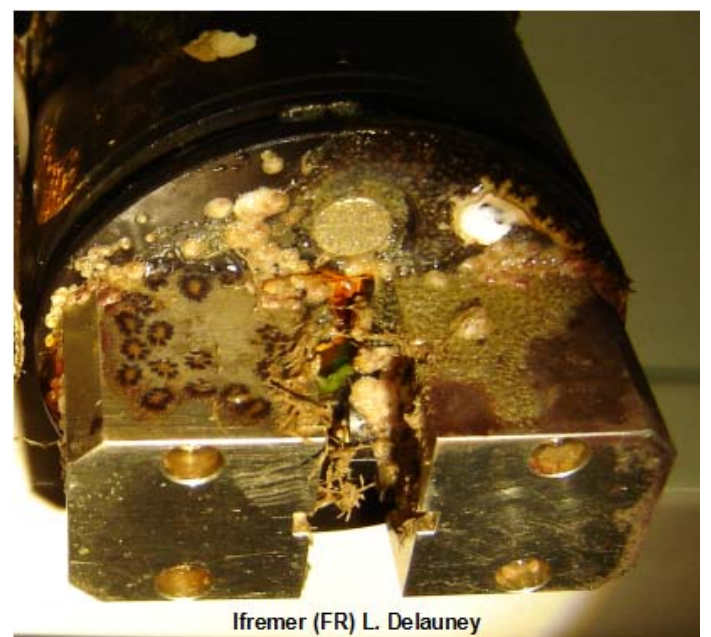

Fig 1 : Fluorometer after

30 days in Helgoland (Germany) during summer

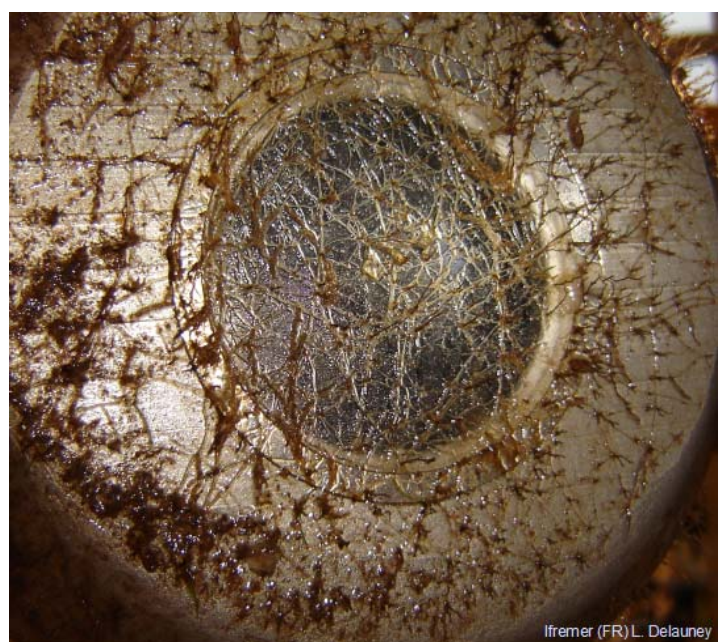

Fig 2 : Transmissometer after 40 days in Trondheim harbour (Norway) during summer

This biofouling development gives rise very often to a continuous shift of the measurements. Consequently the measurements can be out of tolerance and then data are unworkable. Video systems such as cameras and lights can be disrupted by biofouling. Pictures become blurred or noisy and lights lose efficiency since the light intensity decrease due to the screen effect of biofilm and macro-fouling.

As shown in figure 3, after 7 days, due to biofouling settled on the sensitive part of the sensor, a drift can be observed on measurements produced by a fluorescence sensor (Delauney and Cowie, 2002). This type of optical sensor is very sensitive to biofouling since even a very thin biofilm on the optics can interfere with the measurement process and give rise to incorrect measurements. 


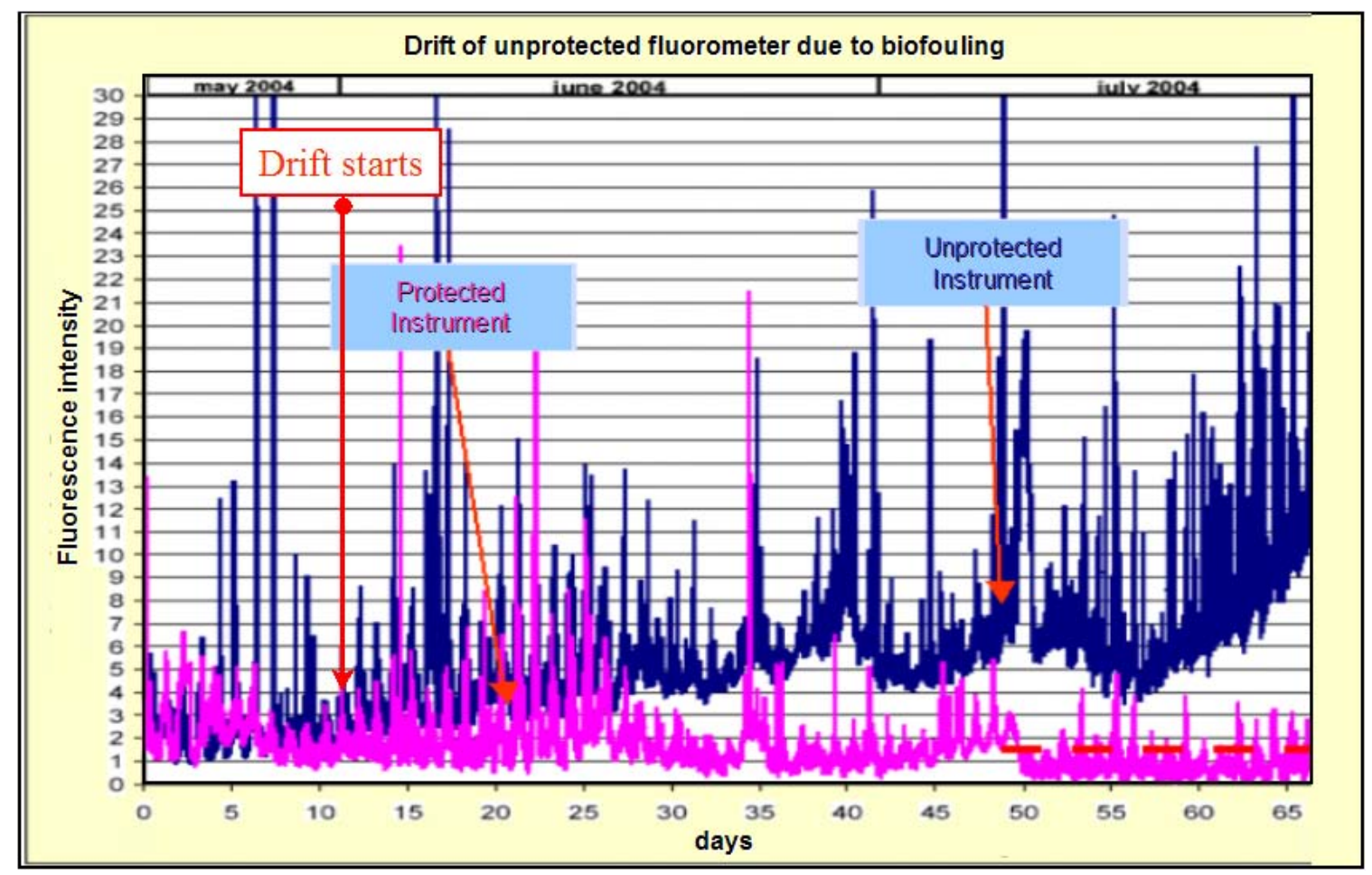

Fig 3 : Drift of an unprotected fluorometer due to biofouling development on the optics

An increase of the sensor response due to biofouling is quite particular to fluorescence sensors, usually the drift observed due to biofouling is a decrease in the response. This can be observed with conductivity sensors (electrode based cells), transmissometers, $\mathrm{pH}$ sensors and oxygen sensors (Clark electrodes and Optodes) (Delauney and Lepage, 2002).

\subsection{Sensor biofouling protection specifications}

Biofouling protection for oceanographic sensors is a difficult task where the specifications should be driven by three important characteristics :

- It should not affect the measurement or the environment.

- It should not consume too much energy, in order to preserve the endurance of the autonomous monitoring system.

- It should be reliable even in aggressive conditions (seawater corrosion, sediments, hydrostatic pressure, ...).

Few techniques are actually used, antifouling paints are not adapted to protect sensors' sensitive parts. For sensors such as optical sensors (fluorometer, turbidimeter, transmissometer, dissolved oxygen), membrane sensors $(\mathrm{pH}$, dissolved oxygen) or electrochemical sensors (conductivity), the interface between the measurement medium and the sensor sensitive area must remain intact.

\subsection{Sensor biofouling protection strategies}

The techniques for biofouling protection for oceanographic sensors can be classified, as shown on the table 1, according to their methods of action :

- Volumetric action : the biofouling protection is acting in a small volume surrounding the sensor area.

- Surface action : the biofouling protection is acting directly on the sensing area of the sensor.

- Active : the biofouling protection is dependent on energy, consequently in most cases it can be turned on and off

- Passive : the biofouling protection does not need any energy, consequently it is always working and cannot be turned off. 


\begin{tabular}{|c|l|l|}
\hline Method of action & \multicolumn{1}{|c|}{ Active } & \multicolumn{1}{c|}{ Passive } \\
\hline Volumetric & $\begin{array}{l}\text { Copper shutter } \\
\text { Chlorine production }\end{array}$ & $\begin{array}{l}\text { Protection ring } \\
\text { Biocide substance leaching }\end{array}$ \\
\hline Surface & $\begin{array}{l}\text { Wiper } \\
\text { Water jet } \\
\text { Ultrasonic sound } \\
\text { Chlorine production } \\
\text { U.V radiation } \\
\text { Bleach injection }\end{array}$ & $\begin{array}{l}\text { Material nature } \\
\text { Biocide coating }\end{array}$ \\
\hline
\end{tabular}

Table 1 : Biofouling protection strategies for oceanographic sensors

(Lehaître et al., 2008)

\subsection{Commercially available techniques}

Three biofouling protection systems for oceanographic sensors are in actual use for operational deployments. These three techniques are commonly used on oceanographic sensors and show for each of them, advantages and disadvantages.

\section{- A purely mechanical device : wipers or scrapers.}

A biofouling protection system using wipers is a purely mechanical process that will need to be adapted to the instrument from the early stages of design. Consequently it can be found on instruments where the sensors' manufacturers have taken into account the biofouling problem. This biofouling protection technique is effective as long as the scrapers are in good condition and as long as the geometry of the sensor head is suitable for this cleaning process. The disadvantage of this technique is mainly the mechanical complexity of the system which gives rise to weaknesses. For example, needing to ensure that the wiper axle is water tight is a major weakness, as well as ensuring the robustness of the wiper motion device. This technique can be found on many oceanographic instruments such as YSI EDS series ${ }^{1}$, Hydrolab's Self-Cleaning sensors ${ }^{2}$, or Wet Labs/Sea-Bird Bio wiper ${ }^{3}$.

\section{- An "uncontrolled" biocide generation system based on copper corrosion mechanism or TBT leaching.}

Protection based on TBT (Tributyl-tin) leaching should no longer be considered as a solution for biofouling protection. Despite the fact that this chemical has proved to be extremely efficient, tributyl-tin compounds have been shown to have deleterious effects upon the environment. TBT was banned for antifouling paints from 2003 and should not be used on ships hulls from 2008 (Champ, 2003 and Evans, 1999). Nevertheless one company still uses this biocide for sensor biofouling protection. This American company, Seabird, has obtained from the U.S. Environmental Protection Agency (E.P.A.) the authorization to use TBT rings in a pumping device coupled to a conductivity sensor. This scheme is coherent since this sensor must be used with a pumping device in order to ensure the sensor's time response compensation and therefore avoid salinity spikinge. When the conductivity sensor is performing a measurement the pumping device is on, consequently the TBT is flushed and it's concentration becomes very low. Therefore there is no danger for the TBT to disturb the conductivity measurement. When the sensor is idle, the pump is off, the TBT concentration can rise inside the measurement cell, which protects it from biofouling.

\footnotetext{
${ }^{1}$ See

https://www.ysi.com/portal/page/portal/YSI_Environmental/Products/Product_Family/Product?productID=EMS_SON01_6600EDS accessed on 09/09/2009

${ }^{2}$ See http://www.hydrolab.com/products/turb_sc.asp accessed on 09/09/2009

${ }^{3}$ See http://www.wetlabs.com/products/wqm/wqm.htm accessed on 09/09/2009
} 
Copper is known for it's biocide properties, and is currently used to protect sensors against biofouling in a variety of ways. The released bivalent $\mathrm{Cu}^{2+}$ interferes with enzymes on cell membranes and prevents cell division (Breur, 2001). For the last five years, some manufacturers have used this protection technique. Some of them build the sensor head totally in copper and add a wiper system to scrape the optics (YSI 6-Series Anti-Fouling Kits ${ }^{4}$ or Wet Labs/Sea-Birds WQM's sensors ${ }^{5}$ ).

A specific item of equipment can be found that allows the user to equip any sensor with a copper cell system, more commonly named a "Copper shutter". A motor drives the mechanism with shutters that open for measurements and close for biofouling protection over the optical windows. It keeps the sensor very close to the copper shutter and when closed the sensor surface is in darkness, which reduces biofouling, and alse allow biocide concentration to increase.

Such protection is not easy to implement on an existing sensor. The copper screen with the stepper motor needs to be placed on the sensor in such a way that the copper screen catches a small volume of water over the sensor measurement interface. An example of such system can be found on a fluorometer (Delauney et al., 2006), figure 4 . In order to maximize the effectiveness of the protection, it was necessary to build up a copper cell and to coat the entire sensor head with copper.
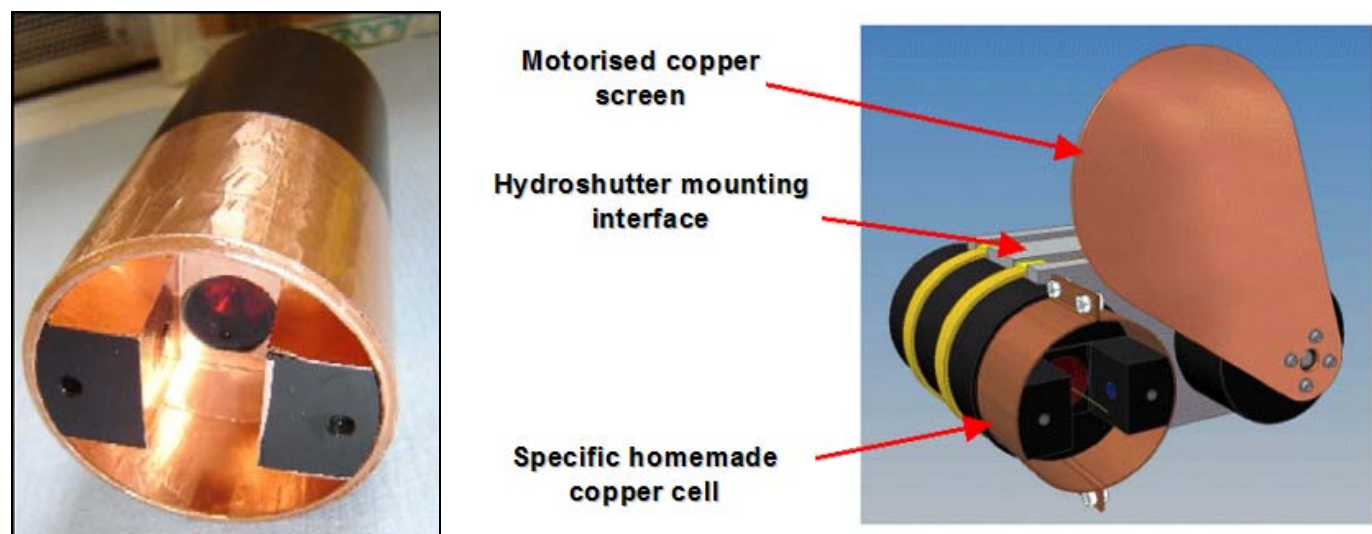

Fig 4 : Biofouling protection with a motorized copper shutter

Results obtained with such a system, when the implementation is made exactly as described above, are quite satisfactory. Similar results were obtained with copper tubing and a copper shutter during experiments on optical instruments by Manov et al. (2004).

\section{- A « controlled » biocide generation system based on chlorine evolution.}

Chlorination has long been used in industrial applications to protect systems from biofouling. Recently it has been used for biofouling protection of in-situ oceanographic instruments.

Two modes of action are used, bleach injection and electrolysis chlorination. These two modes of action are still not widely used by manufacturers.

Bleach injection methods can be found on fresh water monitoring stations and very recently on autonomous monitoring instruments such as the Wet Labs/Sea-Bird WQM's instrument ${ }^{5}$. This scheme requires a reservoir for the chlorine solution and a pump.

The electrolysis chlorination system can be found on monitoring stations (Woerther et al., 1999) (Woerther et al., 1998) and "Ferry Box" instruments that use pumping circuitry, the protection is known as a "global chlorination" scheme (Hengelke et al., 2005). In this way the whole circuitry is protected at the same time as the sensors.

\footnotetext{
${ }^{4}$ See

https://www.ysi.com/portal/page/portal/YSI_Environmental/Products/Product_Family/Product?productID=EMS_ANTIFOULING_KIT accessed on 09/09/2009

${ }^{5}$ See http://www.wetlabs.com/products/wqm/wqm.htm accessed on 09/09/2009
} 
An other electrolysis chlorination scheme can be found on few autonomous sensors, it consists of protecting only the sensing area of the sensor. Thus the electrolysis is performed on a very restricted area and consequently the energy needed is very low and compatible with autonomous deployment. Very few commercial instruments are equipped with such a scheme (Delauney et al., 2009).

\subsection{Non commercial techniques}

Many techniques have been tried for protection of the sensing area of the sensor, while some methods show interesting results in the laboratory, the real in-situ tests at sea can be very disappointing. The complexity of the in situ environment due to seawater composition, temperature variation, light propagation, dynamic flux, and so on, is such that laboratory results are very difficult to realize. Laboratory experiments can be used to perform reproducible tests in order to compare protection effectiveness at early stage of colonization and with unique biofouling species. However, in situ validations are mandatory and should be performed in various places in order to expose the system to a range off biofouling species. It should be considered that in situ biofouling colonization is much more severe than laboratory one.

For the protection methods listed below, some have been tested in the laboratory and in situ trials do not seem to have been performed. Some others have been tested in situ but were not a clear success, which explains why these methods are generally not found as a commercial solution.

\section{- Closed measuring system}

For closed systems, protection based on a dissolving biocide (tablets) can be used. Care should be taken in order not to disturb the measurement. For example, for an optical instrument, spectral absorbance by the biocide can happen. Consequently, a flushing sequence should be involved in order to remove the diluted biocide before performing the measurement. This is one of the major drawbacks with passive protection scheme.

Biocides used for such protection were for example (Manov et al., 2004) chlorine or bromine tablets, Alconox ${ }^{\circledR}$ (Powdered concentrated anionic detergent for manual and ultrasonic cleaning ${ }^{6}$ ) or TBT porous plastic antifoulant rings. The sea trials did not show effective results in every case, the major problems, according the authors, are the difficulty in delivering steady and uniform concentrations of chemical during the course of deployment. In some cases it releases too fast and in other cases it releases too slowly resulting in chemical remaining at the end of deployment and in both cases presence of biofouling at the end of deployment. This results in limited duration for biofouling protection.

\section{- Open measuring system}

Open systems are the most common scheme for oceanographic sensors. This arrangement eliminates many technical problems such as complexity and reliability of the pumping system. However, the sensor is directly exposed to the environment consequently biofouling protection is even more difficult. For example, in most cases the sensor is exposed to ambient light that may promote biofouling development.

With open system the protection element can be placed on the sensing area. This approach is very delicate since the protection material must remain intact during the whole deployment, otherwise metrological problems will occur. For example experiments on an optical sensor have been performed with biocide-doped gel by Kerr et al (2003). The results were promising but some problems of opacity of the gel after a while occured during most of the deployments. In a similar approach Manov et al. (2004) mention usage of low-friction silicon-based compounds on coated glass. Nevertheless, their advice was not to apply any protection material to optical surfaces.

\footnotetext{
${ }^{6}$ See http://www.alconox.com/ accessed on 09/09/2009
} 
Techniques based on irradiation are promising. Possible irradiations are Ultra-Violet, laser, ultrasonic, low frequency sound and vibration. These active techniques have a major advantage, they do not generate any biocide, but on the other hand, the major problem is the power requirement to operate such systems. Manov et al. (2004) mention a commercial oceanographic fluorometer (Wheaton Inc.) protected by U.V. irradiation. In 2009, such protection is no longer used. During the BRIMOM (2002) project, U.V. irradiation has been investigated, despite the power requirement problem; it has been found that the protection is effective only in the vicinity of the U.V. bulb, consequently multiple U.V. sources would be needed to protect the entire sensing area.

Whelan et al. (2006) mention the use of laser irradiation to prevent biofouling by barnacles and diatoms. The results show increasing effectiveness with increasing laser energy density and duration (Nandakumar et al., 2003). Sensor protection trials are not mentioned.

Ultrasonic irradiation effectiveness to control biofilm has been reported by several groups as mentioned by Whelan et al. (2006). The effectiveness of low frequency sound and vibration has been reported by Donsky and Ludyanskiy (1998). Again the energy requirement of such systems is too high for their implementation on autonomous in situ instrumentation

\section{Conclusion.}

Biofouling starts as soon as the sensors are immersed in seawater; it is a natural process that can disrupt sensor measurements in less than a week.

Biofouling protection for marine in situ sensors is a complex problem. Since the quality of the measurement is involved, the fouling protection, especially on the sensitive part of the sensor, must be very effective. On the other hand there should be no adverse effects on the measurements and no modification of the local environment to be monitored.

The ideal protection should be low cost, with low power requirement, easy to install on existing sensors, should not interfere with the instruments or with the environment, and should allow sensor deployment for coastal observatories up to three months and up to one year for deep sea observatories.

Surface treatment based on antifouling paints (biocide release coatings or self polishing coating) are mainly useful to protect the sensor housing.

For two years, manufacturers of instruments are taking into account this functionality in their design. At first, manufacturers implemented mechanical techniques such as wipers. Now they try to combine different techniques on the same instruments. For example, wipers and copper protection are often combined.

Interesting techniques based on irradiation (Ultra violet, ultrasonic) are not used currently for autonomous sensors due to limitation on available energy. Technical improvements in this field are expected in the near future, especially for low power requirement U.V. sources. These techniques are very promising since they do not generate biocide.

Active biofouling protection is very convenient since free biocide production period can be managed in order not to disrupt the sensor and the measured environment. It generally includes cleaning phases between the measurement sequences. Today, the frequently used techniques are bleaching or chlorine generation by seawater electrolysis. Local seawater electrolysis on the sensitive area of the sensor is particularly effective and can be adapted quite easily to existing sensors. Its effectiveness has been demonstrated on various sites and the energy need is compatible with autonomous monitoring. The cost remains low and the device is robust.

Copper shutter systems give effective results to protect the sensitive part of the sensor, but the mechanism is not simple to adapt to existing sensors and the cost remains high.

In all cases, sensors' calibrations should be performed with the biofouling protection system in place, before deployment and after deployment with methods well described in procedural documentations. Moreover, the adverse effects of the biocide released should 
be known in order to arrange biocide free periods during which proper measuremens can be performed.

Biofouling protection for marine environmental sensors needs further evaluation and collaboration between researchers and manufacturers/developers. 


\section{References}

Abou-Ghazala, A., Schoenbach, K.H., IEEE Trans. Plasma Sci., 28,115, 2000

Bearinger, J.P., Terrettaz, S., Michel, R., et al., Nat. Mater., 2, 57, 2003

Blain, S., Guillou, J., Tréguer, P., Woerther, P., Delauney, L., High frequency monitoring of the coastal marine environment using the MAREL buoy, J. Environ. Monit., 6, 569-575, 2004.

Breur, R., Fouling and Bioprotection of Metals, Monitoring and Control of Deposition Processes in Aqueous Environments, Ph.D. thesis, TNO Industrial Technology, 2001

BRIMOM (Biofouling Resistant Infrastructure for Measuring, Observing and Monitoring), Project number EVR1-CT-2002-40023, 2002.

Cen, L., Neoh, K.G., Kang, E.T., Langmuir, 19, 10295, 2003

Chambers, L.D., et al., Surface and Coatings Technology 201, 3642-3652, 2006.

Champ, M.A., Mar. Pollut. Bull., 935, 2003.

Delauney, L., Compere, C., Biofouling Protection for Marine Environmental Optical Sensors, International Conference on Recent Advances in Marine Antifouling Technology (RAMAT), Chennai (Madras), INDIA, 2006.

Delauney L., Compère C., Biofouling protection for marine environmental sensors by local chlorination, Springer Series on Biofilms vol. 4, Marine and Industrial Biofouling, pp119-134, 2009

Delauney, L., Cowie, P., Biofouling Resistant Infrastructure for Measuring, Observing and Monitoring, BRIMOM Report, Project number EVR1-CT-2002-40023, 2002.

Delauney, L., Lepage, V., Biofouling Resistant Infrastructure for Measuring, Observing and Monitoring, BRIMOM Report, Project number EVR1-CT-2002-40023, 2002.

Donsky, D.M., Ludyanskiy, M.L., Zebra Mussel and other aqua. nuisance organ., Proc. 5th Int. Conf., 1998.

Evans, S.M., Biofouling, 14, 117, 1999.

Grisoni, J.M., et al., Station profileur automatique cotière LEO, Atelier Expérimentation et Instrumentation (AEI), Lyon, France, 2007.

Hengelke, C.J., et al., The stationary FerryBos Helgoland: supporting the Helgoland Roads timeseries, European Operational Oceanography: Present and Future, Proceedings on the Fourth International Conference on EuroGOOS, pp174-178, 2005

Holmström, C., Egan, S., Franks, A., McCloy, S., Kjelleberg, S., FEMS Microbiol.Ecol., ,41, 47, 2002.

Kerr, A., et al., Mater. Des., vol 24, p247, 2003

Kerr, A., Cowling, M.J., Beveridge, C.M., Smith, M. J., Parr, A. C. S. The early stage of marine biofouling and its effect on two types of optical sensors. Envin. Int., 4(3), pp. 331-43, 1998.

Lehaître, M., Delauney, L., Compère, C., Real-time Coastal Observing Systems for Marine Ecosystem Dynamics and Harmful Algal Blooms, chap12, Biofouling and underwater measurements, UNESCO, p463, 2008.

Linkous, C.A., Carter, G.J., Locuson, D.B., et al., Environ. Sci. Technol., 34, 4754, 2000

Manov, D.V., Chang, G.C., Dickey, T.D., Methods for reducing biofouling of moored optical sensors, J. Atmos. Ocean. Tech. 21, 6, pp 958-968, 2004.

Morris et al., Zinc oxide photoactive material, U.S. Pat. 6063849, 2000

Nakasono, S., Matsunaga, T., Denki Kagaku, 61, 899,1993

Nakayama, T., Wake, H., Ozawa, K., et al., Environ. Sci. Technol., 32, 798, 1998

Nandakumar, K., Obika, H., Shinozaki, T., et al., Biofouling, 19, 169, 2003.

Nandakumar, K., Obika, H., Shinozaki, T., et al., Water Res., 37, 2311, 2003.

Spears, L.G., Stone, J.H., Environ. Sci. Technol., 3, 576, 1969

Tsukamoto, S., Kato, H., Hirota, H., Fusetani, N., Tetrahedron Lett., 37, 1439, 1996.

US Pat. 4092858, Oceano. sensor with in-situ cleaning and bio-fouling prevention system, 1978.

US Pat. 6060046, Antifouling compositions, 2000. 
Whelan, A., Regan, F., Antifouling strategies for marine and riverine sensors, J. Environ. Monit. 8, 880-886, 2006.

Woerther, P., Coastal environment of the Seine bay area monitored by a new French system of automated measurement stations. EUROGOOS Second International Conference proceeding , 1999.

Woerther, P., Grouhel A., Automated measurement network for the coastal environment. OCEAN'S 98 IEEE - Conference proceeding, 1998.

Wood, P., Jones, M., Bhakoo, M., Gilbert, P., Appl. Environ. Microbiology, 62, 2598, 1996.

Yebra, D.M., Kiil, S., Dam-Johansen, K., Review - Antifouling technology - past, present and future steps towards efficient and environmentally friendly antifouling coatings, Progress in organic Coatings, 50 , 75-104, 2004. 